\title{
Media and Climate Change in Pakistan: Perception of the Journalists in Mainstream Media
}

Sajid Manzoor, Arshad Ali

Centre for Media and Communication Studies, University of Gujrat, Gujrat, Punjab, Pakistan.

*Corresponding Author Email ID: arshad.ali@uog.edu.pk

\section{A B S T R A C T}

Climate change is a high matter of concern for every living being on this planet earth. This research paper explores the perception of Pakistani journalists related to media and climate coverage issues in Pakistan. The results of this paper are based on ten qualitative interviews of the journalists purposively selected from mainstream media in Pakistan covering climate issues. The journalists were of the opinion that lack of resources, old equipment, and poor human skill result in faulty measurements and information which leads to drawbacks in reporting authentic climate change. But fortunately, the actors associated with climate journalism are very well aware of their responsibilities and role.

Keywords: Media, Climate change, Perception, qualitative, Pakistan.

\section{INTRODUCTION}

Climate change is a high matter of concern for every living being on this planet earth. The earth is warming up at a steady pace which is causing severe health, ecological and humanitarian crises just because of the increase in human-caused greenhouse gases. With the passage of every second, climate change is getting more complex global phenomenon as its outcomes are affecting every society either belong to a super advanced and developed country or any $3^{\text {rd }}$ world country in the world. That is why every newspaper tends to extend its coverage because there are diverse media representations of climate change that have mostly concentrated on Western societies, so newspapers belonging to non- Western societies also have focused on covering environmental issues.

There are many media research studies that found that how limited geographical scope of $3^{\text {rd }}$ world countries are watching this climate change scenario. A study conducted in 27 different countries found that how much different countries are preferring climate change phenomena and their state or private media playing its due role in this regard. This study included a sample of 27 countries who have committed themselves to greenhouse gas emission reductions under the Kyoto Protocol such as Germany as well as countries that are strongly affected by the consequences of climate change like India. This study described the development of media attention for climate change in these countries from 1996 to 2010 have been increased very fast concerning the amount of media attention and exploring whether it corresponds with indicators measuring the relevance of climate change and climate policies for a country. This study concluded that climate change coverage has increased in all countries. Still, overall media attention levels, as well as the extent of growth over time, differ strongly between countries. Media attention is especially high in carbon dependent countries with commitments under the Kyoto Protocol. (Andreas Schmidt, 2013)

The media has been working hard to convey this message to the general public around the globe but globally and locally, media reports, news articles, and even editorials give the portrayal to this issue with their own pre-set policies. However, the Media attention is especially high incarbon dependent countries with commitments under the Kyoto Protocol. The way the media report on climate change in English- 
speaking countries, especially in the United States, has been widely studied, while studies of reporting in other countries have been less considerable. A number of studies have shown that particularly in the United States and in the UK tabloid press, the media significantly understated the strength of scientific consensus on climate change established in their environmental control authorities. There are many pieces of evidence which ensure when media gives massage coverage to this issue and when less coverage however a peak in media coverage occurred in early 2007, driven by the IPCC Fourth Assessment Report and Al Gore's documentary An Inconvenient Truth. In 2009, this converge got $50 \%$ higher due to mutual efforts of Climatic Research Unit email controversy and the United Nations Climate Change Conference. Moreover, The Media and Climate Change Observatory team at the University of Colorado Boulder found that

In 2017, we saw media attention to climate change and global warming ebb and flow" with June seeing the maximum global media coverage on both subjects. This rise is "largely attributed to news surrounding United States (US) President Donald J. Trump's withdrawal from the 2015 United Nations (UN) Paris Climate Agreement, with continuing media attention paid to the emergent US isolation following through the G7 summit a few weeks later." (Boykoff, et al., 2017)

Media converge has been changed now about climate change issue. According to some studies, more than a decade of research has been focused just on the patterns that how climate change affects the atmosphere but now media users, newspaper readers are not more interested to know about it even there is too much public's lack of basic knowledge of the science that underlies the 99\% consensus among climate scientists.

In the 1980s, when the concept of global warming was still new to many readers, the Times often referred to the mechanism of greenhouse warming and did so, in some years, in every article. Even after 30 years, this mechanism is seldom mentioned, despite a whole new generation of readers. Now public does not want to know that how scientific consensus has been referred to as a gateway belief by people who study how the public thinks about climate change. They find that, if you can get people to understand that fact, it kind of pries the door open and makes them open to learning more and potentially changing their minds. (Sanders, 2019).

The power of media and its due coverage is obvious, understandable, and apparent. In this globalized world, the media either television, the press, and online play a very pivotal and central role in communicating to the public what happens around the globe, even beyond the star galaxies. In most cases like climate change, where the general audience does not possess direct knowledge or experience of what is happening around, it becomes particularly reliant upon the media to inform about that burning issue. This dependence on the audience creates room for the newsroom to frame any issue in its way. So, the newsroom does not say simply what to think as people do not absorb media messages uncritically so here the setting of agendas any framing of news came forward where every journalist, editor, and field reporter tends to focus public interest on particular subjects, which operates to limit the range of arguments and perspectives that inform public debate. That is why there is always a need to study the role of the media in the construction of public beliefs and attitudes and its relationship to any particular issue, which can bring any social change. (Philo, 2008).

Both at the governmental level, in terms of change through policy action, and at the level of the individual, through commitments to behavioral change, everywhere the role of media and its way to frame any particular issue come under discussion while evaluating any hot topic like climate change. That is why this research work focuses on Pakistani news media including national newspapers and mainstream television channels (terrestrial and satellite both) in the context that how do Pakistani media conceptualize, formulate, and produce news related to climate change. Moreover, it examines that how news stories get selected and what are the processes of choosing and publishing these news stories in Pakistani media.

This article explores the climate change issue in Pakistan in terms of the perception of the media persons involved in climate change coverage. The main objective of this article is;

1. To find about the understandings of the media persons in Pakistan about changes in the climate of the country

2. To explore professional information from Pakistani media persons while selecting, producing, and reporting news about climate change issues and further while maintaining newsworthiness in news content.

This article answers the following research questions. 
1. What are the understandings of the journalists in Pakistan about the climate change issue?

2. What are the sources consumed by Pakistani journalists to understand about climate change issue?

\section{METHODOLOGY}

In exploring the production of news by the journalists in Pakistan, a qualitative interviewing technique was adopted to explore journalistic perspectives about climate change and their priorities while shaping climate news in the newsroom. Using a structured open-ended questionnaire, the journalists were asked about reporting mechanisms and the factors helping or irritating them while covering the issue. All working journalists involved in writing climate change stories/articles were sampling the population. An adequate sample was selected purposively observing the involvement level of a journalist in climate coverage. Ten Journalists were selected purposively adopting a nonprobability sampling technique.

\section{RESULTS AND ANALYSIS}

Climate change is a global risk as its causes and effects are not limited to national borders, but the risks and the responsibility are not evenly spread. Pakistan is facing especially severe impacts in the form of disasters, floods, droughts, rising temperatures, cyclones, and rising sea levels due to global emissions. Pakistan is one of those countries getting hot rapidly due to global climate change. Therefore, this issue is of great concern for the public and private levels. The consequences would be severe if this issue is not taken seriously by the government of Pakistan.

Some Journalists think climate change and rising temperature issue is more vital for Pakistan as compared to terrorism and other issues. Every year we lose not only hundreds of people but crops worth millions because of flood, drought, and heat view. All these calamities happen because of climate change. Pakistan is a country that enjoys a variety of seasons throughout the year. The terrain changes significantly from North to South and so does the climate along with it. The lifestyle of people depends significantly upon their native weather patterns. However, the increase in global warming and changes in weather patterns have also altered the way people live. The annual monsoon rainfall has decreased with long episodes of warm weather and a shrinking winter season. The crop cultivation and harvesting patterns have also been affected. We can develop an 0 understanding of this dire situation by the fact that Pakistan's economic backbone is agriculture and climate change's first target is crops and plantation. If there is a lack of food and no source to drive the economy what will be the impact of this phenomenon on the rest of our lives either directly or indirectly. Climate change is the burning issue of the world and Pakistan is also suffering badly because of the adverse effects of this. We have witnessed frequent floods, heavy rains, and an increase in temperature. The government has launched Billion Tsunami Tree Project as a signature project which shows the sensitivity of the issue. The issue is important in Pakistan because the rising population, huge urbanization, depleting natural resources, and government's little focus on the subject have put it on the list of those countries that are most vulnerable to environmental changes. Pakistan is among the 8 countries most vulnerable.

In Pakistan channels and media outlets don't have space for news related to climate change. Not only news organizations but most people are not interested in climate change news. Pakistan's delegation secured $6^{\text {th }}$ position in completing the commitments in COP25 under the United Nations Framework for Convention on Climate Change (UNFCCC). Moreover, Pakistan is also in the process of revision of Nationally Determined Contributions (NDC). The NDCs include the efforts undertaken by each country to reduce the emissions and the impact of climate change. The purpose of this collaboration is to form an inventory that will measure, report, and verify GHG emissions.

There is no status quo on this specific issue because now media organizations have started paying attention to this serious issue. Print and Electronic media, both, are covering the developments in climate change. Climate change is not the priority of the government like in other developing countries. There is neither any policy-making nor any strategy on the ground to cope with the effects of climate change. Similarly, there is no focus on climate journalism in the newsroom. Most of the editors and other decision makers in the media houses are themselves not only unaware of the subject but also don't encourage the reporters to do some investigative reporting on the subject. Investigative reporting and feature writing on climate change are the two major things that are missing in all forms of media in Pakistani Climate journalists just only focus on the federal 
minister of climate change media talk and no personal experience and research conducted by journalists most of the tv channels primarily focus on political issues and news related climate change funded by NGOs. Although this concept is very common now a day therefore the media organizations are taking much interest in it yet there is much to do. Despite that this issue is not on top of the media agenda in Pakistan. Political, economic, socio-cultural, and scientific, and technological factors influence media coverage of climate change issues in Pakistan. And while some of these might have solutions, there are two primary challenges: access to information for journalists, and the low news value of environmental stories (especially when compared to the overwhelming dominance of politics in this landscape) Firstly, it is technological in the sense that journalists need both the knowledge and resources to access information. Secondly, it is interactive in the sense that journalists need a way to interact with scientists, and vice versa.

Although Pakistani media organizations are working on climate change now sill there is much required to be done on part of the media. Pakistani media remained engaged in covering the political news more but now the pattern is changing, and attention is also being paid to social and environmental issues. There are no favorable conditions in the media organizations to work as an environmental journalist. The journalism is mostly focused on day-to-day coverage, political statements, court reporting, and press conferences.

Ministry of Climate Change is a vibrant public organization in Pakistan that is dealing with the issue through the massive plantation and other projects. The environment and climate change are otherwise a provincial subjects, and provinces have their own priorities to deal with these issues.

Monetary support is an important factor influencing the news media coverage of climate change issues media operates on a business model that depends upon advertisements and subscriptions from the public and private sectors. As far as climate change coverage is concerned, there is little revenue to be had from it as there are no advertisements or subsidies from either state or non-state actors. As a result, the media does not project the issue of climate change as much as other more financially incentivized topics. As one electronic media journalist comments:

Media provide a platform to disseminate information on the mass level but at the same time, media offers time and space to the third party to sell its idea or commodity. This is purely a commercial procedure that can be utilized by advertisers or investors interested to promote the concept of climate change.

We have a controlled media system and those who are controlling media have no interest in climate change and rising temperature. Changes in economic resources affect coverage of climate changes all over the world. In a country like Pakistan where the economy is hardly ever findings, covering and studying, and reporting climate change becomes a difficult task. Reporting climate change requires extensive study and critical evaluation of the obtained data. The latest equipment required to measure and keep a check on the instruments which monitor the weather phenomenon are expensive and require special skills to be operated. These shortcomings act as a hurdle in the way of authentic reporting of climate change in Pakistan since only theoretical data is not enough, statistical, and practical data is equally important to highlight the changes but is not reliable due to lack of resources.

The majority of media organizations are facing a shortage of funds. Scarcity of economic resources compels media organizations for downsizing which ultimately affects the less important beats like climate change because the major focus remains on politics and crime. There is little or zero investment of media houses on reporting climate change. The TV channels don't give space to the issue on the pretext of "rating." Every reporter learns on his own, on the job. At dawn, never been given training on climate change issues. Training provided by other organizations. Resources are the biggest hindrance in coverage of climate change related issues because reporters have to travel far and wide, to remote areas to cover the actual impact of climate change on the lives of people, farmers, and pastoralists.

Along with basic equipment and gadgets, a journalist must have some training to cover climate change because it involves a sort of sensitivity. Unfortunately, Pakistani media is lacking the training to this effect. No sources in terms of time, finances, and newsroom facilities, etc. are available to understand and report on climate change issues in Pakistan. Every reporter learns on his own, on the job. At dawn, never been given training on climate change issues. Training provided by other organizations. It's a personal initiative always in Pakistan. If a journalist wants to report on the issue, they will have to take personal initiatives to find out the 
stories and manage all other things like resources required for traveling to cover them.

One reporter has 3 to 4 news beats and climate change one of the news channel authority provides less priority on climate change. But we find the most illuminating approach for understanding the barriers faced by journalists in Pakistan attempting to provide adequate coverage of climate change issues is the structural approach. This approach focuses on the news values, norms, and newsgathering sources that influence media coverage, and it is here we find the richest soil for our analysis. The incumbent government in Pakistan is focusing much on the Climate change issue. So, the media in Pakistan have much content to cover. The climate journalism actors need to have good coordination for the sake of gaining maximum advantages.

I don't think they have any role. Climate change is a growing phenomenon. No matter how much we try to eradicate it is hard to put the Earth back on its previous track. We are most likely to move forwards now without having a reset button. In this regard, Journalism is going to lay a significant role since it is the major source of spreading the word. Climate journalists have a huge responsibility to report this active change taking place.

Pakistani media is fairly open, though when thinking specifically about climate change, a lack of access to scientific expertise is a clear hindrance. More interestingly, Pakistan's relationship with politics makes the political-economic nexus an especially interesting one because political news is what is perceived as generating interesting news content (and thereby generating advertising revenue). Surprisingly, climate change is not viewed as a political issue

Pakistani media is focusing on this issue since the global weather temperature is growing rapidly. Most media houses depute specific media cells to cope with this issue. I hadn't read any news related to climate change in local newspapers for long. Climate change was never taken seriously until its consequences became apparent and unavoidable. The extended summer season and shrinking winter along with irregular changes in weather patterns like increased temperature and shortage of precipitation have diverted the attention of the government and NGOs towards climate change. The government of Pakistan Tehreek e Insaaf has made sure that climate change and related dynamics are the top priorities of the government and private sector. This is also changing the attitude of all the government and private institutions including the media houses to take this issue seriously and support the cause of fighting climate change with greener techniques and tree plantation. We have witnessed a sudden change in the attitude of media where once the only reported news regarding weather was the forecast now, we can see reports regarding the effects of climate change.

Pakistani media is taking the climate change issue very seriously. Organizations are paying more attention to this engulfing issue. Climate change is behind all major natural disasters, so, media have acknowledged it as an emerging issue in Pakistan. As mentioned above, news organizations need to give priority. Every media organization has its own editorial choices to cover the issues, but unfortunately, no outlet considers climate change as an issue to report on.

Media does not contribute to climate change issues appropriate coverage; Pakistan's media has confined the subject of climate change to event-oriented coverage This issue is directly connected with the media ecosystem so the more strong the media ecosystem is the better this issue would be treated. From morning to midnight, they don't have any space for climate change, they only want news about politics and crime.

As compared to the international coverage of climate change, the contribution of Pakistan in this regard is almost equal to zero. It still has a long way to go. The researchers found out that the reports of media on climate change are limited and inadequate. Moreover, Urdu media hardly ever reports on climate change as compared to the English media. According to the National Council of Environment Journalists, only 2.8\% of the total news coverage is given to environmental news. Thus, we can assume that the Pakistani media does not report as much on climate change as the international media and as much is required. Moreover, Pakistani media entertains a wide range and variety of audiences in Pakistan consequently, addressing and reporting climate change becomes a necessity as it affects each and every individual directly and indirectly and each individual must act to try to least slow down this phenomenon. Same as the answer to question number 12. Economic resources are the backbone of climate change related issues as journalists need resources for traveling, boarding, and lodging to interview people hit by the effects of climate change.

Media does not contribute to climate change issues' 
appropriate coverage; Pakistan's media has confined the subject of climate change to event-oriented coverage This issue has become a global issue now. The whole world is taking this issue seriously therefore Pakistani media is also giving much attention to this issue. As compared to the international coverage of climate change, the contribution of Pakistan in this regard is almost equal to zero. It still has a long way to go. The researchers found out that the reports of media on climate change are limited and inadequate. Moreover, Urdu media hardly ever reports on climate change as compared to the English media. According to the National Council of Environment Journalists, only 2.8\% of the total news coverage is given to environmental news. Thus, we can assume that the Pakistani media does not report as much on climate change as the international media and as much is required. Moreover, Pakistani media entertains a wide range and variety of audiences in Pakistan consequently, addressing and reporting climate change becomes a necessity as it affects each and every individual directly and indirectly and each individual must act to try to least slow down this phenomenon. The reporting of Pakistan media on climate change is very limited due to limited resources, low knowledge of decision makers (editors, news editors) on the subject, and media houses' reluctance to invest resources in it. Journalists cover climate change because masses of Pakistan are bearing heavy losses due to natural disasters which are caused by climate change. Journalists prefer stories that attach some importance to the general public. All reporters are assigned areas to cover. They do understand it's happening, and information needs to get out to people. If a reporter is covering climate change news, it must be their initiative. Event-oriented coverage, contact with the ministry of climate change, no specific research was done As I am a part of a state TV Channel where this issue is dealt with on a priority basis. Being state TV channel news based items and especial interest programmers are prepared for this issue. As I mentioned above there is no such procedure.

In my institution, a whole unit is allocated to reporting climate change and environmental phenomena. My institutions give equal importance to climate change in print media. Moreover, this unit remains in contact with national institutions such as NDMA, PDMAs, EPA, and PMD in order to lay its hands on firsthand authentic information and update regarding the change in weather and climate patterns and its consequences. Reporting, thus, helps in mainstreaming all the institutions and filling the gaps in order to address the issue. We don't have any specific instructions from our organization to cover the climate change aspect. It is purely the discretion of the reporter whatever topic he wants to cover, but, if someone covers the climate change aspect, it is broadcasted on priority. Personally, I cover the subject case on priority. There are neither separate climate change desks in Pakistan's media houses nor specialized sub-edit to edit reports on climate change with having a grip on the subject. Usually, a reporter is assigned the beat of climate change along with other half dozen beats and he only remains limited to file press releases of the Ministry of Climate Change. Climate changes need to be given priority. ZERO - My organization like the other ones isn't interested in covering these issues.

Media talk, press release, contact with NGOs research, and talk with victims. event ordinated news. Being a media practitioner, I often work on this issue. I produce news items and packages on this issue to highlight the importance of this issue. I didn't file a single story on climate related issues for the last two years.

Being a journalist, I have always believed in getting firsthand information regarding any topic and the same goes for climate change. First of all, I directly contact the local authorities and meet with the residents in order to get the full picture of the extent of the damage and the result being faced by them. This helps me in getting baseline information regarding that issue. Afterward, I try to extract its reasons by consulting research work and getting a complete picture of the issue starting from its cause effect and result which helps me in drafting a complete report on the issue. I am working on climate change as I have developed an interest in this subject. Usually, I conduct interviews of experts but before conducting interviews I do research on the topic through google and research papers that are being published across the world. I further categorize the topic whether it's a current issue of climate change or it might arise in the future.

I select my topics by conducting some research on presently available content. At the same time, I interact with the experts and people working on climate change in non-government organizations to get some ideas for my stories. 


\section{DISCUSSION AND CONCLUSION}

Pakistan is ranked among the top ten countries of the world that are worst hit by climate change. Pakistan is losing a significant amount of its resources annually to climate change related incidents like floods and erosion, besides facing food shortages. The Pakistani media does not, seemingly, give climate change issues sufficient coverage, not only in relation to international standards but also in relation to regional standards Pakistan's media has confined the subject of climate change to event-oriented coverage. Climate change has become a big challenge for the whole world including Pakistan and due to the importance of this issue, climate journalism is being considered seriously by all media networks especially by state media in Pakistan. According to Pakistan Environmental Journalists, Climate Change is not among editorial priorities in Pakistan. However, with the change in climate, this attitude is changing. Nowadays most journalists are covering this issue without prior training. Covering Climate Change requires knowledge of the field but most of the journalists working in the field have little knowledge regarding the natural phenomenon and the changes occurring. Another drawback is the lack of reliable and authentic data. But the drastic change due to climate change is opening the eyes of the media and has diverted its attention to this issue. Environmental Journalism is still in its budding stage, but it is going to become an important branch of journalism in Pakistan in the future. Not given enough attention. Pakistani media hardly reports on climate change unless there is flash flooding, glacial lake outbursts in the northern regions. Climate change remains an under-reported subject in Pakistani media and journalists are also not trained to handle the subject proactively. Unfortunately, we have these organizations only in papers or they only talk about climate change when a calamity happens. Anything that is out of normal, hazardous to the environment, and human health makes news. We have to do a lot of things before pitching a story and getting it approved from editors, so this all can't be described here.

Pakistan Environmental Protection Act passed in 1997 delineated the powers designated to various sectors of Environment protection including Pakistan Environmental protection Council, Pakistan Environmental Protection Agency, and Environment Tribunals. PEPA has succeeded in bringing all these organs of a single platform and working in unison with
PEPC working as a legislator, EPA working as executive branch, and tribunals working as courts for environmental causes. Each of these organs has powers to keep a check and balance on the other branch and work together to make sure that the environment is kept safe.

Climate change is still not the priority of media, we have a controlled media system and those who are controlling media have no interest in climate change and rising temperature. Changes in economic resources affect coverage of climate changes all over the world. In a country like Pakistan where the economy is hardly ever findings, covering and studying, and reporting climate change becomes a difficult task. Reporting climate change requires extensive study and critical evaluation of the obtained data. The latest equipment required to measure and keep a check on the instruments which monitor the weather phenomenon are expensive and require special skills to be operated. These shortcomings act as a hurdle in the way of authentic reporting of climate change in Pakistan since only theoretical data is not enough, statistical, and practical data is equally important to highlight the changes but is not reliable due to lack of resources. Journalists believe that both government and non-government organizations are receiving funds from international bodies for promoting climate change awareness, but these funds are not reaching the media despite being intended to run advertising campaigns highlighting environmental issues. As a result, the media does not give much attention to climate change issues. Finance, working routines, and time are big challenges in our media. As mentioned earlier, reporting climate change is still not in the top priorities of the newsrooms among the myriad of changing political situations in Pakistan. Still, the major source of information is the institutions working on climate change and natural disaster management such as Environmental Protection Agency or the NDMA, or PDMAs. Moreover, the ongoing research or the findings of international platforms regarding the changes in climate in Pakistan. Moreover, media coverage of climate change is also financed by the media houses. A whole beat is allocated to the reporting of climate change which remains in contact with the concerned institutions and ensures smooth reporting.

In addition, the sources are bound to get authentic and reliable statistics and information regarding the changes in the physical and chemical dynamics of the weather 
and related factors such as rain patterns, melting, flooding, agriculture, etc. However, the lack of resources, old equipment, and poor human skill result in faulty measurements and information which leads to drawbacks in reporting authentic climate change. The actors associated with climate journalism are very well aware of their responsibilities and role. They know well the importance attached to the subject. The coverage of climate change can be increased, and the scope of climate journalism can be enhanced if the organizational structures of media houses support both that cannot be seen anywhere. The role is extremely important. Our job is to convey the message through stories that matter. They all are interlinked, and organizations working on the subject should be forthcoming to develop a good working relationship with journalists to report on the issues.

\section{REFERENCES}

Andreas Schmidt, A. I. (2013). Media attention for climate change around the world: A comparative analysis of newspaper coverage in 27 countries. Global Environmental Change, 23 (5), 1233-1248.

Boykoff, M., Andrews, K., Daly, M., Katzung, J., Luedecke, G., Maldonado, C., et al. (2017). A Review of Media Coverage of Climate Change and Global Warming in 2017. "A Review of Media Coverage of Climate Change and Global Warming in 2017". Media and Climate Change Observatory, Center for Colorado: "A Review of Media Coverage of Climate Cha Media and Climate Change Observatory, Center for Science and Technology Policy Research, Cooperative Institute for Research in Environmental Sciences, University of Colorado.

Philo, G. (2008). Active audiences and the construction of public knowledge. Journalism Studies, 09 (04), 4535-4544.

Sanders, R. (2019, September 19). In media coverage of climate change, where are the facts? Retrieved August 10, 2020, from www.news.berkeley.edu: https://news.berkeley.edu/2019/09/19/inmedia-coverage-of-climate-change-where-arethe-facts/

Svoboda, M. (2020, March 10). Media coverage of climate change in 2019 got bigger - and better. Retrieved August 10, 2020, from www.yaleclimateconnections.org: https://yaleclimateconnections.org/2020/03/me dia-coverage-of-climate-change-in-2019-gotbigger-and-better/

Weingart, P. A. (2000). Risks of Communication: Discourses on Climate Change in Science, Politics, and the Mass Media. Public Understanding of Science, 261-283.

Andreas Schmidt, A. I. (2013). Media attention for climate change around the world: A comparative analysis of newspaper coverage in 27 countries. Global Environmental Change, 23 (5), 1233-1248.

Bennett WL. (2002). News: the politics of illusion. New York: Longman, New York.

Billi, M. B. (2019). What is the 'Social' in Climate Change Research? A Case Study on Scientific Representations from Chile. Minerva 57, 293-315.

Boykoff, M., Andrews, K., Daly, M., Katzung, J., Luedecke, G., Maldonado, C., et al. (2017). A Review of Media Coverage of Climate Change and Global Warming in 2017. Media and Climate Change Observatory, Center for Colorado: Center for Science and Technology Policy Research, Cooperative Institute for Research in Environmental Sciences, University of Colorado.

Christie, M. C. (2015). Putting transformative learning theory into practice. Australian Journal of Adult Learning, 55 (01).

Dietz, T. \&. (2020). Climate Change and Society. Annual Review of Sociology, 46 (01).

Flew, T. (2016). Entertainment media, cultural power, and post-globalization: The case of China's international media expansion and the discourse of soft power. Global Media and China, 01 (04), 278-294

Hoogendoorn, G. \&. (2020). The influence of climate change beliefs on the perceived consequences of climate change. Journal of Risk Research, 01 (13), 29-35.

Howie, P. \&. (2013). A beautiful metaphor: Transformative learning theory. International Journal of Lifelong Education, 32 (06), 816-836.

IPCC (Intergovernmental Panel on Climate Change). (2013). Summary for Policymakers. In: Climate Change 2013: The Physical Science Basis. Contribution of Working Group I to the Fifth Assessment Report of the Intergovernmental Panel on Climate Change. Cambridge, United Kingdom and New York, NY, USA: Cambridge University Press. 
Mezirow, J. (2009). Transformative learning theory. In J. Mezirow, and E. W. Taylor (Eds) Transformative Learning in Practise: Insights from Community.

PACMAS Baseline Study. (2013). PACMAS (2013) Baseline Study (State of Media and Communications Report). PACMAS Organization.

Philo, G. (2008). Active audiences and the construction of public knowledge. Journalism Studies, 09 (04), 4535-4544.

Sanders, R. (2019, September 19). In media coverage of climate change, where are the facts? Retrieved August 10, 2020, from www.news.berkeley.edu: https://news.berkeley.edu/2019/09/19/inmedia-coverage-of-climate-change-where-arethe-facts/

Svoboda, M. (2020, March 10). Media coverage of climate change in 2019 got bigger - and better. Retrieved August 10, 2020, from www.yaleclimateconnections.org: https://yaleclimateconnections.org/2020/03/me dia-coverage-of-climate-change-in-2019-gotbigger-and-better/

Swain K.A. (2012). Mass Media Roles in Climate Change Mitigation: Handbook of Climate Change Mitigation. New York, NY: Swain K.A. (2012) Mass Media Roles in Climate Change Mitigation. In: Chen WY., Seiner J., Suzuki T., L Springer, New York, NY.

Weingart, P. A. (2000). Risks of Communication: Discourses on Climate Change in Science, Politics, and the Mass Media. Public Understanding of Science, 261-283.

Publisher's note: EScience Press remains neutral with regard to jurisdictional claims in published maps and institutional affiliations.

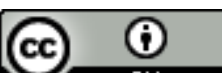

(C) Open Access This article is licensed under a Creative Commons Attribution 4.0 International License, which permits use, sharing, adaptation, distribution, and reproduction in any medium or format, as long as you give appropriate credit to the original author(s) and the source, provide a link to the Creative Commons license and indicate if changes were made. The images or other third-party material in this article are included in the article's Creative Commons license, unless indicated otherwise in a credit line to the material. If material is not included in the article's Creative Commons license and your intended use is not permitted by statutory regulation or exceeds the permitted use, you will need to obtain permission directly from the copyright holder. To view a copy of this license, visit http://creativecommons.org/licenses/by/4.0/.

(C) The Author(s) 2021. 